\title{
Comparative analysis of cultural influence of Chinese and western TV programme hosts
}

\author{
Xiaomei Xing
}

\author{
Institute of Media and Communications, Inner Mongolia University for the Nationalities, \\ Tongliao, 028000, China
}

\begin{abstract}
Keywords: Chinese and western; TV programme host; cultural influence; difference; mass culture; cultural responsibility
\end{abstract}

\begin{abstract}
Chinese TV programmes started to be popular widely and develop rapidly. TV program hosts also became national idols. The academic circle is continuously studying and developing growth track and development law of hosts. This paper mainly analyzes and compares cultural influence of current Chinese and western TV programme hosts and propose relevant suggestions for future reference.
\end{abstract}

From the reform in 1978 to present, it has been for over 30 years for Chinese socialist economic development. With economic development, spiritual cultural construction proceeds continuously. TV programme as a vital part of cultural construction has become an important communication tool of spiritual culture. The functions of hosts as the direct media of driving TV programmes and connecting with audiences directly and TV programme representatives are irrefragable. Chinese and western cultures have immeasurably vast differences since their birth. So, their cultural influences are also greatly different.

\section{General development situation of Chinese and western TV programme hosts}

(I) General development situation of Chinese TV programme hosts

The development of TV programme hosts in China is fundamentally different from that in western countries. TV programmes and broadcasting programmes have kept pace with each other and developed jointly since their date of birth. In 1980s, the earliest TV programme hosts in China were born. On July 2, 1980, CCTV-1 launched the programme of Observation and Consideration the first time. Its host was Pang Xiao who was an excellent announcer. He is also the first real TV programme host in Chins. This marked Chinese TV programme host field stepped into a new height. The reform of TV programme hosts better develops with the reform and opening and accelerated socialist modernization course. This paper divides its development into three stages for discussions.

1. Budding development stage (1980-1990)

This stage is budding and rapid development period of Chinese TV programme hosts. In this period, new TV programme in China - News Magazine started to gradually come into view of common people. Due to some limitations of economic development level, the number of TV sets was limited. This to some extent made people watch TV together and greatly increased influence of TV programme hosts. Li Peihong - the host of News Magazine as a hostess of a new generation of TV programmes made a stage pose first, walked out of the studio and really participated in early-stage interview and post-production. This triggered great echoes and gained wide approval and welcome from all sectors of society. Later, CCTV followed up a victory with hot pursuit and launched two programmes hosted by hostesses - Super Variety Show and Zhengda Variety Show. Ni Ping and Yang Lan who just graduated from mass media universities came into people's view and have become widely known hostesses. Apart from CCTV, various local TVs were reluctant to show weakness. Shanghai TV also launched some host show programmes which made a great stir and launched some program hosts with local features, such as Ju Ping, Gao Liping and Cheng Qian. 
They were all excellent hosts selected and cultivated locally.

2. Initial development stage (1990-2000)

Through the budding stage, the development of Chinese TV program hosts entered the second development stage. Pang Xiao as the first announcer named "host" made great efforts in future programmes. The first TV program about people's livelihood played in CCTV - Why is it difficult for people in Beijing to have cheap and fine vegetables won general good reputation from all sectors of society. In this stage, many excellent hosts and TV programmes were born, such as famous CCTV host - Zhao Zhongxiang who formally appeared in the capacity of a host. The programme he hosted - Intelligence Competition for Middle School Students in Beijing is the first knowledge contest programme in China. Since then, the tide of such programmes has been lifted and continues till now. Besides, children's programmes also started to formally appear - Qiqiaoban was a very famous children's programme. "Sister Ju Ping" formally entered the heart of vast children and was deeply loved by vast children due to her appetency and infection.

3. Golden development stage (2000-now)

In this stage, due to continuous and rapid development of socialist economy, on the one hand, material living standards of Chinese people have improved continuously. On the other hand, this to some extent greatly promotes rapid development of socialist TV programmes. However, in this stage, international situations are not stable. The Iraq War and "911 Event" promoted a large batch of famous battlefield hosts and journalists. As a Chinese journalist who first arrived in Baghdad in the Iraq War - Lv Qiuluwei gave rise to a great sensation and was rated as "battlefield rose". She immediately brought important repot from the front line for Chinese people and thus gained general praises from all sectors of society. The outbreak of SARS also facilitated Chai Jing, Wang Jie and other journalists. The reports from the front line made them win respect from others. We can call this stage the golden period of the development of TV programme hosts. In this stage, TV programmes gradually present such features as professionalization, demassification, channel and entertainment. Host selection competitions and training activities continue to thrive and develop in this stage. National relevant departments explicitly state that ideological and moral qualities and expertise must be valued during host training. It is required to cultivate hosts with pertinence according to different programme demands. Meanwhile, "Oscar" in Chinese host field - Golden Mike Award started to be set up officially. It can make nationwide hosts to fully display themselves and gain good effects.

(II) General development situation of western TV programme hosts

Basic information about the development of western TV programme hosts is roughly same time China, but due to different culture and life style, there are also some differences. Chinese TV programme hosts generally show solemnity and strong expertise. However, western TV programmes are closely related to the life of vast audiences and are very close to people's daily life. In the development course of western TV programmes, "talent show" programme is most well-known. Its huge influences are beyond people’s expectation. In the hosting process, hosts can even study and discuss sensitive political departments and macroeconomic control as well as boldly deliver their opinions. This cannot be seen in any programme in China. The reason why talent show programmes can analyze and discuss state affairs and other sensitive matters without scruple may be closely related to western nobility. Western nobility owns the right to discuss state affairs due to their honorable identity. After the birth of broadcast, they further tended to express their opinions via medium and made more people discuss. This to a large extent promotes the birth of talent show programme. Since its birth, it has been approved and focused on by people all over the world. An increasing number of countries started to imitate western countries to set up talent show programmes suitable for their national conditions. But, they cannot surpass western countries all the time and especially America. Now, talent show program has become an important mark of western TV programmes and is the significant milestone in the field of spiritual culture. Since the host of talent show programme is the representative of the program, the host also receives attention. The host's cultural transmission also has very important effects in social development. 


\section{Comparative analysis of cultural influence of Chinese and western TV programme hosts}

(I) Cultural influence of Chinese TV programme hosts

Based on actual situations of Chinese TV programmes in current stage, this paper sums up cultural influence of Chinese TV programme hosts as follows:

1. Audiences pay general attention and all citizens welcome

For Chinese TV programme hosts, they own extraordinary influence in the hearts of audiences and even play a role of appealing others. For example, CCTV recorded a significant TV programme - My Long March in order to better celebrate the 70th anniversary of the Red Army's long march in anti-Japanese war. This programme was hosted by a famous host in China - Cui Yongyuan. Within just five days when the programme announcement was published, tens of thousands of candidates registered for it, including famous signers, actors and general's wife etc. All sectors of society involved in it. This largely shows important influence of TV programmes and their hosts. This programme finally gained good effects in the whole process. The final economic income was fully used for construction and transformation of schools and hospitals in the red tour in China. Therefore, this programme reached win-win purpose. Both the programme and its host are deeply penetrated into people's daily life and impose great influences on production and life.

2. Classics lack and vulgar events prevail

TV programs and their hosts give rise to great influences in people's daily life. Their positive energy gradually prevails in China's socialist construction and development. However, due to fast propagation speed and wide coverage, many negative impacts also occur. In recent years, rapid development of science and technology makes network media boom. But, due to the lack of professional supervision, plentiful malicious information spreads quickly. Sister Furong, charging BMW case and similar cases generate very adverse impacts on socialist spiritual civilization. Moreover, in current TV programmes, classical programmes gradually cut down. Hosts speak vulgarly in programmes in order to boost audience rating. This goes against heritage and development of spiritual civilization.

(II) Cultural influence of western TV programme hosts

Western culture upholds liberalism and stresses personal interests, which is well reflected in programmes. But this to some extent causes material civilization is mismatched with spiritual civilization and generates very bad impacts. Thus, individualism and terrorist forces prevail in western countries.

Meanwhile, western TV programmes and their hosts deliberately emphasize pragmatism which is mainly reflected in their consumption view. Media stress economic benefit and continuously advertise various products in the programmes. This seriously influences formation of correct cultural values and outlook on life.

\section{Conclusions}

Oriental and western cultures are greatly difference since their dates of birth due to special social environment and social system. TV programme hosts as important media spreading spiritual culture have received universal attention and own transcendental cultural influence. Therefore, in daily work, TV programme hosts should play the model and guide role to guide the audiences to establish correct outlook on life and values.

\section{References:}

[1] Yin Hong, Yang Chenghu, Culture - creativity - industry: 3D space of Chinese TV - an interview with Professor Yin Hong, vice-president of Tsinghua School of Journalism \& Communication (Journal of Communication University of China), 2007(01)

[2] (British) Andrew Goodwin, (British) Garry Whannel, translated by Wei Liqing and Wang Lili, 
Truth of TV. Central Compilation \& Translation Press, 2001

[3] Hu Zhifeng, Zhou Jianxin, from “propaganda products”, “works” to "products” - three development stages of China TV programme innovation over the past 50 years [J]. Modem Communication (Journal of Communication University of China), 2008(04)

[4] Du Zhihong, Symbol presentation of Chinese cultural influence and communication innovation - interpretation of Walk in Chinatown [J]. Modem Communication (Journal of Communication University of China), 2011(04)

[5] Zeng Zhihua, Summary of traditional Chinese medicine - comment on Hong Tao, host of Traditional Chinese Medicine in CCTV-4. Modem Communication (Journal of Communication University of China), 2008(05)

[6] Yu Songming, Chen Wei, Analysis of constitutional features of Golden Mike Award winners case study of winners in 2006-2010 [J]. Voice and Screen World, 2011(11)

[7] Zhang Hongxun, Comparative study of Chinese and American TV news program hosts AHCHOR TV news program host: from America to China [D]. Zhengzhou University, 2002.

[8] Chen Wei, Analysis of entertainment and cultural quality of popular TV programmes - thoughts from the programme of Hong Kong TVB Minutes to Fame [J]. Southeast Communication, 2005(08) 